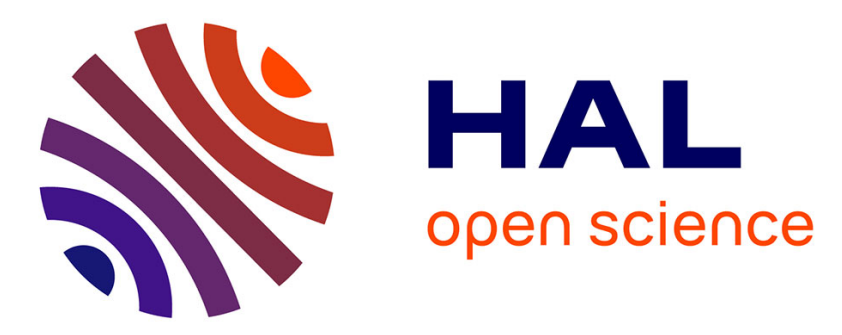

\title{
External-cavity based optoelectronic oscillator stabilization (Conference Presentation)
}

Michael Joe Wishon, Daeyoung Choi, Tobias Niebur, Nathan Webster, Yanne Chembo, Evgeny Viktorov, David Citrin, A. Locquet

\section{- To cite this version:}

Michael Joe Wishon, Daeyoung Choi, Tobias Niebur, Nathan Webster, Yanne Chembo, et al.. External-cavity based optoelectronic oscillator stabilization (Conference Presentation). SPIE Photonics Europe, Apr 2018, Strasbourg, France. 10.1117/12.2306088 . hal-03084779

\section{HAL Id: hal-03084779 \\ https://hal.science/hal-03084779}

Submitted on 21 Dec 2020

HAL is a multi-disciplinary open access archive for the deposit and dissemination of scientific research documents, whether they are published or not. The documents may come from teaching and research institutions in France or abroad, or from public or private research centers.
L'archive ouverte pluridisciplinaire HAL, est destinée au dépôt et à la diffusion de documents scientifiques de niveau recherche, publiés ou non, émanant des établissements d'enseignement et de recherche français ou étrangers, des laboratoires publics ou privés. 


\title{
External-cavity based optoelectronic oscillator stabilization
}

\author{
Michael J. Wishon ${ }^{\mathrm{ab}}$, D. Choi ${ }^{\mathrm{ab}}$, T. Niebur ${ }^{\mathrm{ab}}$, N. Webster ${ }^{\mathrm{ab}}$, Yanne K. Chembo ${ }^{\mathrm{ac}}$, \\ E. A. Viktorov ${ }^{\text {d, D. S. Citrin }}{ }^{\mathrm{ab}}$, and Alexandre Locquet $^{\mathrm{ab}}$ \\ aUMI 2958 Georgia Tech-CNRS, Georgia Tech Lorraine, 2 Rue Marconi, 57070 Metz, France \\ bSchool of Electrical and Computer Engineering, Georgia Institute of Technology, Atlanta, \\ Georgia, 30332-0250, USA \\ ${ }^{\mathrm{c} O p t i c s}$ Department, CNRS, Franche-Comté Electronique, Mécanique, Thermique et \\ Optique-Sciences et Technologies Institute, Université Bourgogne Franche-Comté, 25030 \\ Besançon, France \\ ${ }^{\mathrm{d} N a t i o n a l ~ R e s e a r c h ~ U n i v e r s i t y ~ o f ~ I n f o r m a t i o n ~ T e c h n o l o g i e s, ~ M e c h a n i c s ~ a n d ~ O p t i c s, ~} 199034$ St. \\ Petersburg, Russia
}

\begin{abstract}
The stabilization of a relatively simple optoelectronic oscillator tunable across the X-band based on a laser subjected to optical feedback is achieved. Specifically, a resonance effect based on locking the two inherent frequencies of the system, as well as, self-modulation were utilized to achieve a sub-ps phase jitter.
\end{abstract}

Keywords: microwave photonics, semiconductor lasers

\section{INTRODUCTION}

Since the first demonstrations of optoelectronic oscillators (OEOs) as highly stable RF sources, ${ }^{1,2}$ they have continually grown in popularity due to their many applications in radar and communications, ${ }^{3,4}$ as well as, sensing and measurement. ${ }^{5}$ The paradigm has been improved by increasing stability and tunability utilizing various schemes. ${ }^{6-15}$ Recently, a relatively simple X-band tunable OEO was demonstrated which did not require opticalto-electrical conversion by utilizing the high-frequency dynamics of the terminal voltage from a semiconductor laser subjected to optical feedback. ${ }^{16}$ Specifically, an OEO tunable from 6.79 to $11.48 \mathrm{GHz}$ was demonstrated, but with phase jitter of $\sim 10$ ps. In laser systems subjected to feedback, there are two major frequencies whose interplay creates rich dynamics, namely the relaxation-oscillation frequency $f_{R O}$ and delay frequency $f_{\tau}$. $f_{R O}$ is generated in the dynamics when either the optical intensity or voltage dynamics are perturbed from steady-state leading to an energy exchange between photons and inversion in the laser active medium. The other frequency, $f_{\tau}$, comes from the inverse of the external-cavity optical round-trip time, $\tau$ (Fig. 1). The OEO is based on the dynamics of several periodic solutions that can be observed for wide ranges of feedback, ${ }^{17}$ and the frequency of the observed microwave oscillation in the optical intensity and voltage is given by the laser's $f_{R O}$. The relaxation oscillation frequency varies monotonically with the injection current $J^{18}$ and therefore can be used as a tuning parameter.

Two important features for most OEO applications are frequency tunability and stability. Using the method based on optical feedback, it is possible to access the entire X-band with simple adjustment of the pump current $J$. Thus, these systems offer wide tunability but to date lack the phase stability needed for many applications. Here we demonstrate how to stabilize such systems.

\section{OEO SYSTEM AND STABILIZATION}

The OEO is based on an unpackaged multi-quantum well laser operating at $1550 \mathrm{~nm}$ subjected to optical feedback from an external mirror a fixed distance away. ${ }^{18}$ The amount of light re-injected back into the laser, represented by $\eta$ in Fig 1 , is controlled by the relative angle of a quarter-wave plate mounted on a rotational stage to a fixed

Correspondence: Alexandre Locquet - alocquet@georgiatech-metz.fr 


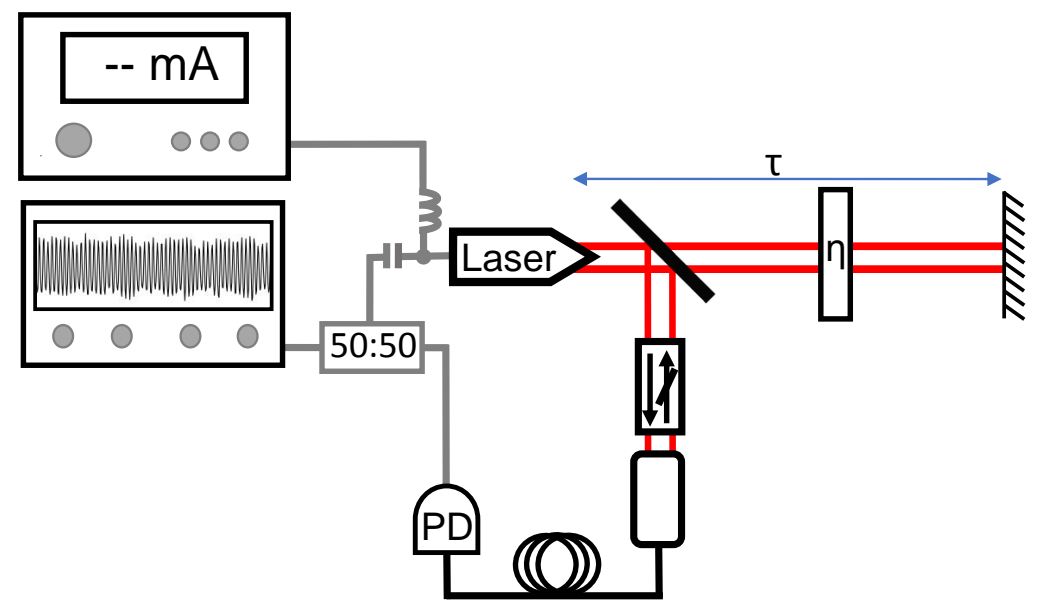

Figure 1. A schematic diagram of the free-space OEO. A mirror is placed a fixed distance from the laser, which causes the laser's output to be re-injected after a time delay, $\tau$. The feedback strength is represented by $\eta$, and the strength is set by the rotational relationship between a fixed linear polarizer and a quarter-wave plate on a rotational stage. PD and 50:50 stand for photodiode and splitter, respectively. A bias-tee is connected to the laser to separate the DC and AC components of the signal. In the optical detection path, an optical isolator and fiber coupler are utilized to limit back reflections and couple the free-space optical intensity into fiber for detection and self-modulation.

linear polarizer aligned to the natural polarization of the laser. ${ }^{16,18}$ A beam splitter was placed in the optical path in order to obtain a signal for self-modulation as well as measurement. A photodiode (Newport 1544-B $12 \mathrm{GHz}$ ), a high-frequency RF probe (Cascade Microtech - $40 \mathrm{GHz}$ ), bias-T (Mini-circuits - $18 \mathrm{GHz}$ ), electrical splitter (Mini-circuits $12 \mathrm{GHz}$ ), and oscilloscope (Agilent 80804B - $12 \mathrm{GHz}$ ) were utilized to measure the timing jitter.

The first improvement was based on electrical self-modulation of the system as shown schematically in Fig. 1. Essentially, a beam splitter was placed in the external cavity such that half the optical power could be extracted and converted to electrical energy by a photodiode. Half of the resulting electrical signal was added to the laser's DC nominal current using a bias-T and RF probe. The second improvement was to set $f_{\tau}$ to be an integer multiple of $f_{R O}$. Specifically, $f_{R O}$ was fixed to the desired RF frequency using the DC pump current. Next, $\tau$ was adjusted by changing the mirror's position relative to the fixed laser $(\tau$ in Fig. 1$)$, until $f_{R O}=m f_{\tau}$ with $m$ an integer.

\section{RESULTS AND DISCUSSION}

In order to characterize the OEO, time-series were utilized to measure phase jitter and ascertain spectral purity. Figure 2 shows the calculated FFT spectra of the unstabilized and stabilized microwave time-series. From the spectra, there is an increase in spectral purity and stability given by a reduction in the peak to pedestal ratio. In order to quantify this, phase jitter was calculated using a demodulation technique, ${ }^{16}$ and it was possible to ascertain that the timing jitter was reduced from 10 ps to sub-ps $(\geq 0.8 \mathrm{ps})$ for all frequencies, but this method is limited by the sampling frequency of the oscilloscope. We suspect the improvement in noise and jitter are the result of increased coherence and cycle-to-cycle averaging created by self-modulation and resonance locking.

\section{CONCLUSION}

A stable optoelectronic oscillator tunable across the X-band is demonstrated using a laser subjected to optical and electrical feedback. The stability of the OEO is characterized by sub-ps timing jitter. This system utilizes off the shelf telecom components and could be made very compact. 


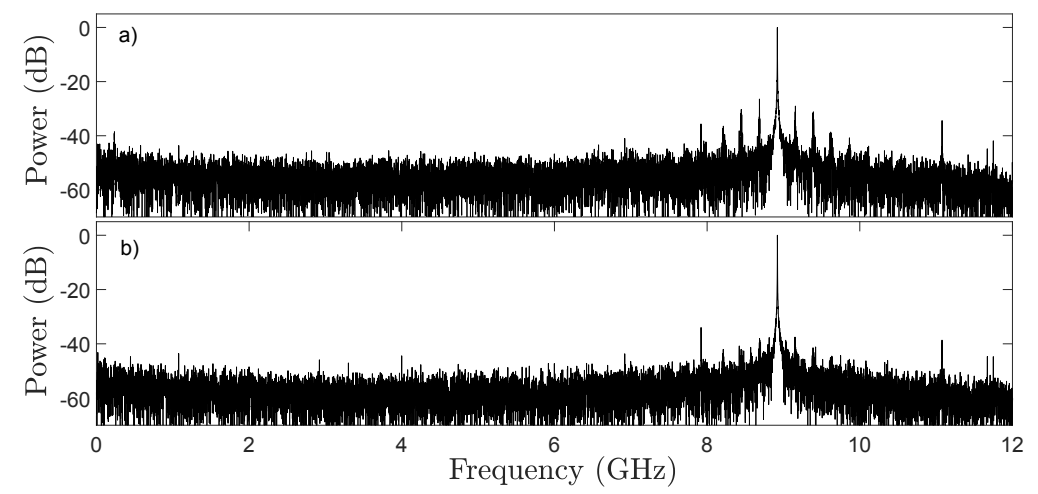

Figure 2. The calculated spectra of a representative OEO operating at $9.1 \mathrm{GHz}$ with (b) and without (a) stabilization. A significant reduction in side-band noise is observed in the spectra for the stabilized case which indicates a reduction in jitter and noise.

\section{Acknowledgments}

We gratefully acknowledge the financial support of the Conseil Régional Grand Est and Fonds Européen de Développement Régional (FEDER).

\section{REFERENCES}

[1] Yao, X. S. and Maleki, L., "High frequency optical subcarrier generator," Electronics Letters 30(18), 15251526 (1994).

[2] Yao, X. S. and Maleki, L., "Optoelectronic microwave oscillator," JOSA B 13(8), 1725-1735 (1996).

[3] Maleki, L., "Sources: The optoelectronic oscillator," Nature Photonics 5(12), 728 (2011).

[4] Devgan, P., "A review of optoelectronic oscillators for high speed signal processing applications," ISRN Electronics 2013 (2013).

[5] Zou, X., Liu, X., Li, W., Li, P., Pan, W., Yan, L., and Shao, L., "Optoelectronic oscillators (oeos) to sensing, measurement, and detection," IEEE Journal of Quantum Electronics 52(1), 1-16 (2016).

[6] Bogataj, L., Vidmar, M., and Batagelj, B., "A feedback control loop for frequency stabilization in an opto-electronic oscillator," Journal of Lightwave Technology 32(20), 3690-3694 (2014).

[7] Yao, J., "Photonic generation of microwave arbitrary waveforms," Optics Communications 284(15), 37233736 (2011).

[8] Yu, J., Yao, X., and Maleki, L., "Compact optoelectronic oscillator with ultra-low phase noise performance," Electronics Letters 35(18), 1554-1555 (1999).

[9] Davidson, T., Goldgeier, P., Eisenstein, G., and Orenstein, M., "High spectral purity cw oscillation and pulse generation in optoelectronic microwave oscillator," Electronics Letters 35(15), 1260-1261 (1999).

[10] Lasri, J., Devgan, P., Tang, R., and Kumar, P., "Ultralow timing jitter 40-gb/s clock recovery using a self-starting optoelectronic oscillator," IEEE Photonics Technology Letters 16(1), 263-265 (2004).

[11] Volyanskiy, K., Salzenstein, P., Tavernier, H., Pogurmirskiy, M., Chembo, Y. K., and Larger, L., "Compact optoelectronic microwave oscillators using ultra-high q whispering gallery mode disk-resonators and phase modulation," Optics Express 18(21), 22358-22363 (2010).

[12] Savchenkov, A., Ilchenko, V., Byrd, J., Liang, W., Eliyahu, D., Matsko, A., Seidel, D., and Maleki, L., "Whispering-gallery mode based opto-electronic oscillators," in [Frequency Control Symposium (FCS), 2010 IEEE International], 554-557, IEEE (2010).

[13] Pochet, M., Naderi, N. A., Li, Y., Kovanis, V., and Lester, L. F., "Tunable photonic oscillators using optically injected quantum-dash diode lasers," IEEE Photonics Technology Letters 22(11), 763-765 (2010).

[14] Fedderwitz, S., Stohr, A., Babiel, S., Rymanov, V., and Jager, D., "Optoelectronic $k$-band oscillator with gigahertz tuning range and low phase noise," IEEE Photonics Technology Letters 22(20), 1497-1499 (2010).

[15] Liang, W., Eliyahu, D., Ilchenko, V., Savchenkov, A., Matsko, A., Seidel, D., and Maleki, L., "High spectral purity kerr frequency comb radio frequency photonic oscillator," Nature communications 6, 7957 (2015). 
[16] Chang, C.-Y., Wishon, M. J., Choi, D., Dong, J., Merghem, K., Ramdane, A., Lelarge, F., Martinez, A., Locquet, A., and Citrin, D., "Tunable x-band optoelectronic oscillators based on external-cavity semiconductor lasers," IEEE Journal of Quantum Electronics 53(3), 1-6 (2017).

[17] Kim, B., Locquet, A., Choi, D., and Citrin, D., "Experimental route to chaos of an external-cavity semiconductor laser," Physical Review A 91(6), 061802 (2015).

[18] Chang, C.-Y., Choi, D., Locquet, A., Wishon, M. J., Merghem, K., Ramdane, A., Lelarge, F., Martinez, A., and Citrin, D., "A multi-ghz chaotic optoelectronic oscillator based on laser terminal voltage," Applied Physics Letters 108(19), 191109 (2016). 